Periodica Polytechnica Architecture, 49(1), pp. 86-91, 2018

\title{
Digital by Nature: The Cephalopods and the Algorithms
}

\author{
Tibor Pálóczi ${ }^{1}$ Péter Lassu* \\ 1 Department of Design, Faculty of Architecture, Budapest University of Technology and Economics, \\ H-1521 Budapest, P.O.B. 91, Hungary \\ *Corresponding author, e-mail: peter.lassu@rajzi.bme.hu
}

Received: 14 December 2017, Accepted: 25 April 2018, Published online: 25 May 2018

\begin{abstract}
This Abstract presents the realisation of the experimental wooden structure, known as "Ammoniterasz" - (Ammonites+Terrace). During the making of this structure, the authors tried to analyse the practical usage of algorithmic design and the generative method. In the generative design, the 3D shape of the real structure is made using an algorithm with predefined editing rules. With an algorithm, it is possible to carry out a real-time structural analysis, together with different kinds of optimisation calculations and production methods. The compilation of the algorithm is created either with scripts or with a 3D graphic surface, which results in a flow chart, by another name, a visual script. Unlike the traditional shaping methods, with generative design, the result is not a static one, but a process which can offer countless options for the pre-defined design (geometric) program. To use a biological analogy: in this way, the designer is creating the rules of a growing process.
\end{abstract}

\section{Keywords}

generative design, optimisation, wood structure, workshop

\section{Introduction}

In summer 2016, the Hello Wood workshop organized in Csopak. The wooden sculpture, known as Ammoniterasz was created by the students and teachers of the Technical University of Budapest, (BME) Faculty of Architecture, within the workshop. This curiosity of a multifunctional (meditation, recreation) sculpture-like building is in the realisation and in the process of making it. It uses the methods of digital modernisation, and techniques of manual construction in parallel.

\section{The site}

The sites were drawn from among the participants. By this method, one of the most interesting sites, the geopark of the Balaton-felvidéki Nemzeti Park's headquarter (Balaton-felvidéki National Park Directorate - Fig. 1) was picked by the BME team. This two-hectare site is not only a well-maintained park, but with several nature trails, the visitor soon gets to know the geological history of this area. Moreover, this area is part of the Bakony-Balaton geopark, which also contains the Balaton-felvidék and the Bakony areas. It won the UNESCO Global Geopark title in 2012 .

\section{Client needs}

The most important aspect of this sculpture was that it had to fit perfectly into the concept of the park: to introduce the natural organisms in a spectacular, experimental and understandable way. The educational aspects play a huge role in the life of the directorate. They present regular geotourism, geological and nature education programmes for the public, and have direct contact with the local population.

An important requirement was that a functioning sculpture should be created next to the site. The installation should be readily visitable, accessible to visitors and interactively, usable in the field. The construction should be partly spectacular and partly educational, connecting to the presented geological values. It became clear immediately that it should be a representative specimen from the studied geological formation of the park.

\section{Connections}

The region is extremely rich in ammonites both locally and internationally. These creatures were widespread limestone cephalopod animals in the oceans of the geological period (Fig. 2). About 66 million years ago, they became 


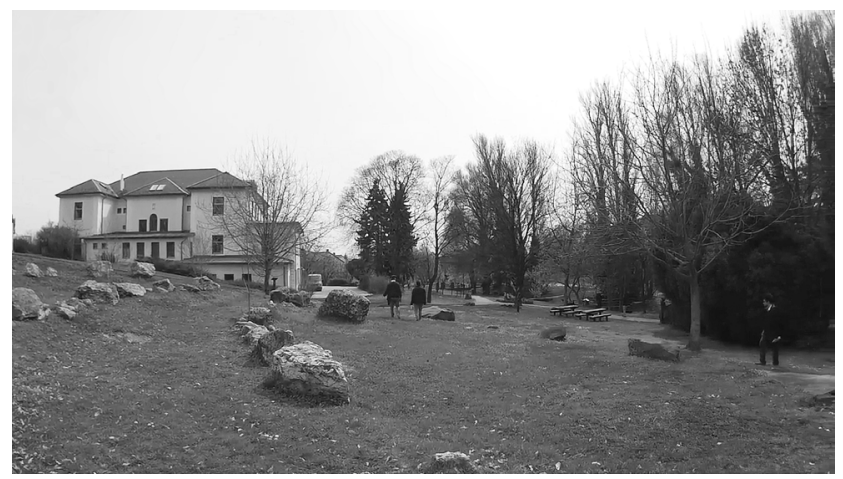

Fig. 1 Balaton-felvidéki National Park Directorate

extinct parallel to the dinosaurs. Due to their external calcium skeletons, the well preserved remaining fossils - at first glance - are similar to snail shells. However, they are more closely related to octopus, squid and cuttlefish. The examples from this site are Balatonites. The shells of the invertebrates, which belong to the class of the cephalopods, follow a mathematically recognised pattern nicely illustrating a quote from Galileo Galilei: "the big book of nature is written by the language of mathematics".

In nature, we can see many examples of how mathematical rules take shape in a form. The twisted frame of the ammonites follows the spiral geometry (logarithmic, golden ratio - Fibonacci spiral). In contrast to the vertical twisted snail shape, the external shapes of ammonites twist only in one, dorsal, clockwise plane. The appearance of geometrical forms in nature is not accidental: the self-reproduction ambition of nature forms in the shape of these animals. The fossils have preserved the outline of these animals with the park displaying many examples.

The concept was created by the client needs and the fitness and characteristics of the surroundings. The shape of the furniture-like sculpture involves the structure and geometry of ammonites. Moreover, it is possible to hide in the shaded interior, sit on it, chat, or just rest on the densely distributed strips. As the realised sculpture displays the negative shape of ammonites, (the solid stone conserves the shape of the fossil) so the wooden structure displays the external shape of the twisting Fibonacci spiral.

\section{Design}

"When nature continues as architecture, it means that natural forms, or more correctly, their morphology, the metamorphoses caused by natural forces, etc. are incorporated into our architectural idiom, parallel to Euclidean form language, or even as a replacement for it.” (Pietilä, 1985)

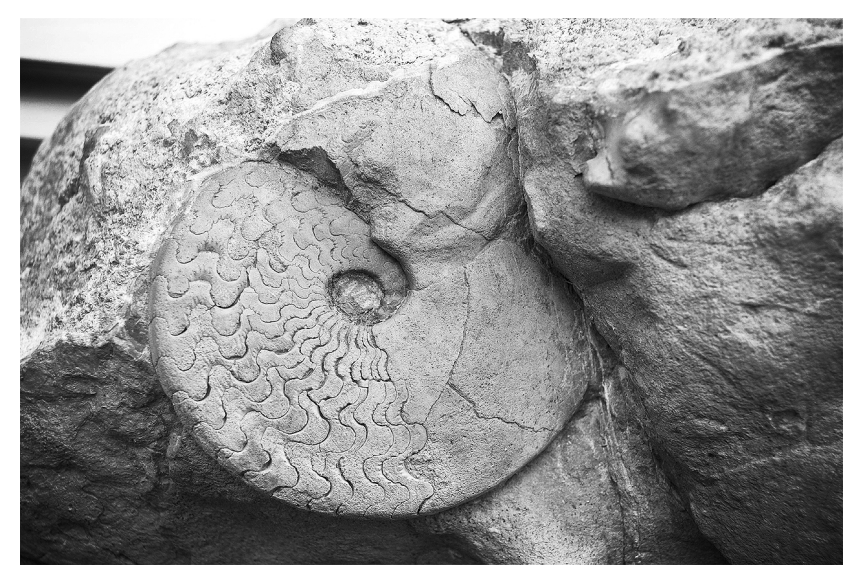

Fig. 2 Hungarites (Barnag, Hungary, Middle Triassic (Anisian)) - Owner: Vörös, Attila and Főzy, István - Source: https://www. europeana.eu/portal/en/record/2023901/NatEu_HNHM_ Palaeontology_HNHM_PAL_Hungarites_jpg.html

In the appearance of the Ammoniterasz, the geometric shape is only secondary. In other words, the context of the structural elements was designed not by the final form but by the generating logic. To avoid the trap of copying the natural form, it is important to study the flow of the natural construction. The design process results in a new kind of architectural logic, one that expands our existing design logic.

The shape of the natural organism is determined by two things: first is DNA, the second is the outside influences. DNA (genotype) is a code to organise the cells to make something bigger. In the case of the outside influences, we have to think about influences like gravity, flow, vibration, climatic changes and natural status. These issues determine the process that results in the final shape, the phenotype. (The same complexity can be seen in other organisms that create intricate emergent structure from simple components, for example, the movement of a flock of birds, where the whole is more than a sum of the parts.)

During the design period, the most important aspect was creating the form constructing process. In the paperbased design method, the stages are documented step by step. Sometimes, retracing and redesign are part of it. All the results are answers to the questions of the ongoing process. The process ends when it is accepted by the designer. Usually, it is limited by time or human knowledge.

In nature, the form finding method is always seeking a structural optimum. Consequently, the end product cannot be freely formed or generated without structural or construction principles; although, there could be many good solutions for one question. 


\section{Classic rates}

Its shape is characterised by a flat based spiral, which is describable by the Fibonacci sequence. Every quotient of the sequence is equivalent to a direct number of the golden ratio. (In mathematics, two quantities are in the golden ratio if their ratio is the same as the ratio of their sum to the larger of the two quantities. (Fig. 3))

The parts of the project follow this golden ratio, and the installation is from 34 layers (frame) and 1597 pieces, both are Fibonacci numbers.

The Fibonacci sequence follows a simple rule. With the same easy rule, a spiral can also be constructed in squares by hand. Beyond the two-dimensional plan, an examination of the 3D shape shows its complexity. The double curved surface is intricate, and hard to do by hand. At this point, normal computer modelling would be sufficient. It is still common, that "computer aided design" plans are mostly for representing hand drawn and designed houses only replacing the earlier manual drawing techniques. With this method, the designer tries to exploit the opportunities of the computer. The computer is not a direct part of the design method; it is not used for the output, it is the designing device.

The next part of the study explains why it was important to have a higher-level tool usage and how it determines and reacts to the design.

\section{Getting closer}

Nature almost never uses straight lines or flat surfaces; this belongs to the human perspective. However, during construction, it is much easier to work with these elements. To build a double curved surface or the inverse of it, usually, it is divided into slices, or segments, resulting in several parallel slices next to each other. After joining the slices, the characteristic of the curvilinear form is shown clearly. In the second option, linear components are used to develop the surface using linear rods or panels. In the design process, both logics have been utilised.

The flat section, rod-type wood material was the main limitation. It was provided by team Hello Wood. One significant issue was that beyond a certain length, some of the rods start to bend and are unstable; a characteristic of wood under certain conditions and probably also the size of the section being used. A limitation of the joints also comes from the dimensions of the wood. Only screws were used, not carpentry joints so as not to weaken the tiny joints more than was necessary. Another restriction

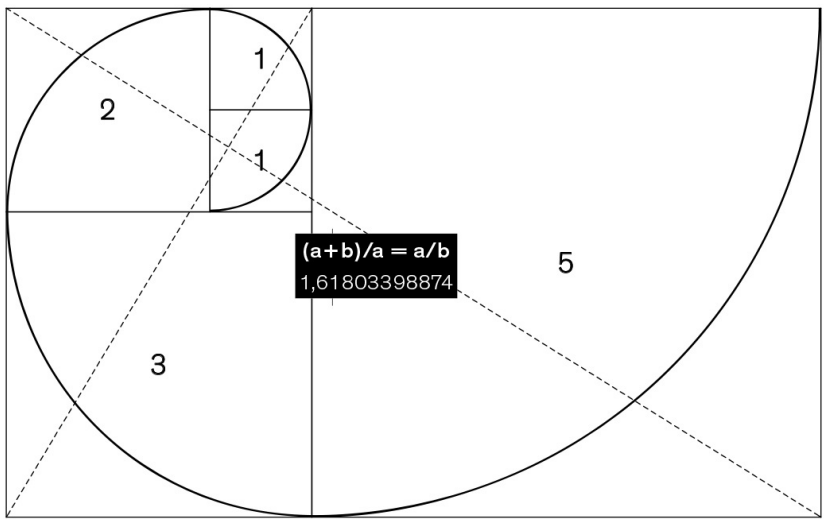

Fig. 3 A Fibonacci spiral using quarter-circle arcs inscribed in squares of integer Fibonacci-number side, shown for square sizes 1, 1, 2, 3 and 5.

was the amount of the usable material: a $2.5 \mathrm{~m}^{3}$ pine tree. Consequently, a solution was required that allowed for the double curved surface, did not need further support benches, and could be generated relatively easily. Moreover, it uses the material in the most optimal way.

After several trials (Fig. 4), a radial directional solution was decided on; this had further advantages during the design process:

- the rod based different cross-sections of the Ammoniterasz creates a futuristic view of the sculpture. As with Toyo Ito's serpentine pavilion, the hole punched surface pattern is not only a visual effect but also a structural component; it is the same with the "Ammoniterasz"(Fig. 5).

- by using thin wooden rods, we have to be aware of the lengths, they should be under deflection lengths

- with this structure, we could minimise the waste.

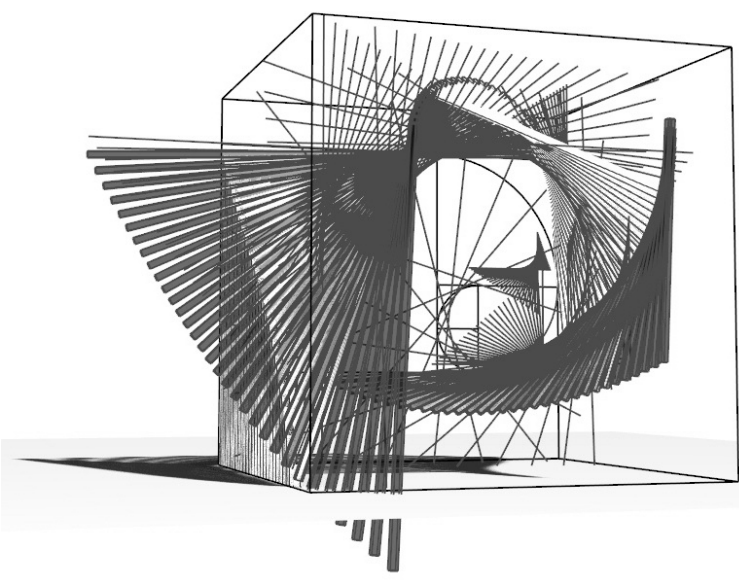

Fig. 4 Preliminary studies of straight lines 


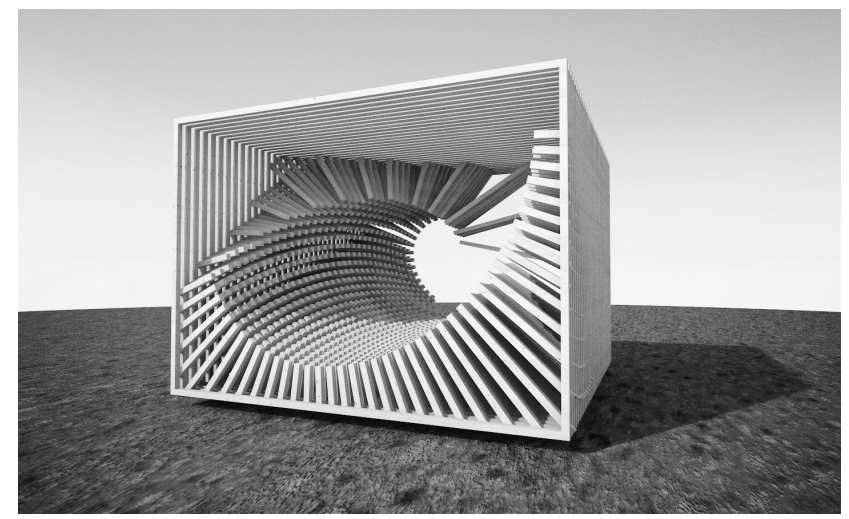

Fig. 5 First concept of wooden construction

\section{Generative Design}

“The logic and clarity of Frei Otto's forms result from his strict and systematic adherence to the rule of natural economy and subordination of extraneous considerations to the instructions obtained from the process of form discovery. He would never "force" or attempt to pervert the intrinsic structural logic of form to achieve an architectural artifact." (Drew, 1976)

The imagined wooden structure was defined by several boundary conditions.

- The usability array of the rods (sit, and lay back)

- The ammonite's double curved shape

- The sections and lengths of the rods

- The useable wood material, and reducing waste

- Easy and fast to build

As a result of several initial criteria, it was necessary to build a model that makes it possible to study the different solutions. The parametric model is not a static form that defines the final form, but a flexible model, which can be modified by the parameters. During the process of making a model like this, it is not necessary to define the shape; we have to define a structure which generates it.
In computer science, the process has two base components: one is the parameter or variable, the other is the rule. The parameters provide the flexibility, the rules in the context of the Ammoniterasz define the complex position of the rods in relation to each other. (with rules, we can define not only geometric rules but also, for example, the strengths in the rods (pressed vault). The two together create the designing process.

In this way, during this process, the model is completed by an algorithm, defined by rules and parameters (Fig. 6). The product of this algorithm is usually created on a graphic surface, resulting in a flowchart - a visual script. The generative design is a design of a construction process, which finally, can produce countless solutions for one - for example - geometrical task.

The algorithm of Ammoniterasz consists of three main parts: In the first, we can see settings for the whole geometry; the second generates the inner chain geometry, with the third creating the documentation. Each of them has their own rules and parameters, while also connecting to each other. The base geometry defined in the first part affects the rod allocation, which affects the documentation directly.

In the first part, the frame geometry and the double curved shape can be controlled. The proportion of the frames is fixed by the golden ratio, but they can have different side lengths. To realise this, the parameters are narrowed to real material lengths.

After the first step, one part of the Ammonite's shape (double curved) can be modified separately. The middle part generates the rod array, considering the distance, the rod cross section and the base surface too. With these two parameters, the final fine-tuning is possible within a minute. It was especially useful because the final sizes of the rods were different from the base parameters. With a further parameter-pair the twist of the array was easily adjustable.

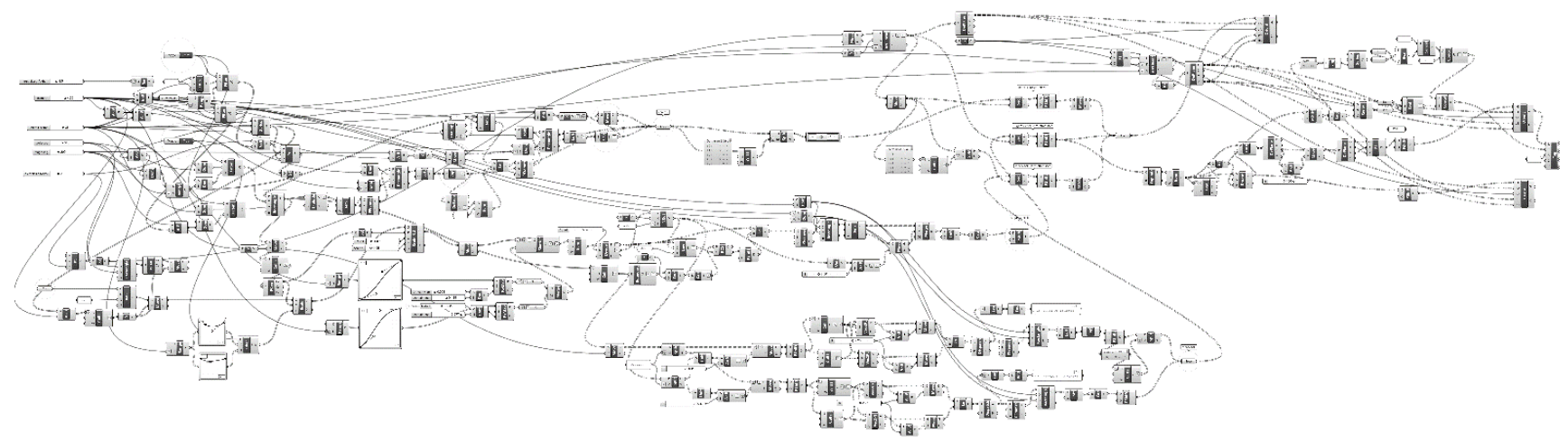

Fig. 6 Visual script for the 3D parametric model of Ammoniterasz 
The end of the flowchart makes the documentation for the construction (Fig. 7). The importance of which is presented in the next section. The plans are in an associative connection with the parametric model. As the 3D model is changing so is the schedule drawings and its texts.

With the parametric model, the idea became displayable and variable. It was possible to test several solutions. Thanks to generativity, the complexity of the double curved surface and arraying the rods remained manageable, despite all the parts having different lengths and angles. The usage of the parameters and the definitions create interactions between the structural and the architectural design methods.

\section{Construction}

The Hello Wood work camp is about construction. The motto of it is learning by doing. We did not just have to take care of the design, but also the construction process. The one-week long camp meant only four full working days in reality. Compared to the complexity of the plan, this time would have been short if everything (scale, consign, mark) had had to be carried out on site. Moreover, work with hand tools takes more time than digitally controlled manufacturing and assembly.

The main question was, how is it possible to bridge this obstacle between the context of the digital design and the actual material, time, information, and tools. Briefly: it is necessary to connect the digital design and the manual construction.

\section{Rewrite of a proven method}

The answer to the previous question is the " prefabrication template" or "template drawing" (Fig. 8). Through the

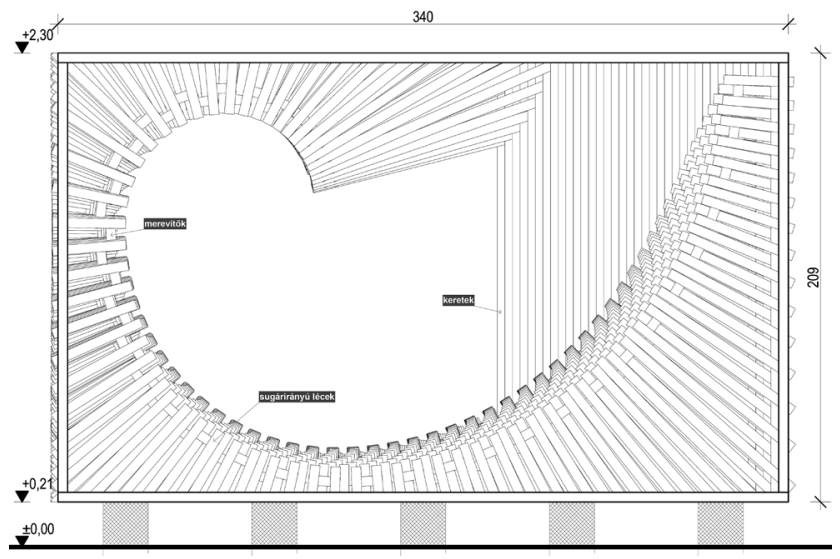

Fig. 7 Automatically generated elevation drawing from the visual script construction of traditional carpenter roof structures, it makes it possible to make the main sections with less failure, and more precisely. To carry out the installation, this method was also used. Compared to the traditional roof template, it was not enough to use only one section for the construction. We built 34 different frames, which had their own template drawings. With visual scripts, we can not only make complicated geometries but can retrieve any data from the plan too. If required, it would also be possible to create an automatic schedule according to the elements. To generate the sections, and to have text for the parts would have only required some more details in the script. After printing the 1:1 scale detail drawings, we could hold in our hands the modern " templates" created by digital techniques. The printed digital details solved the control of the different elements, eg. their place and their connections (Fig. 9). During the construction process, all the team members were able to work continuously; the working parts were easy to organise.

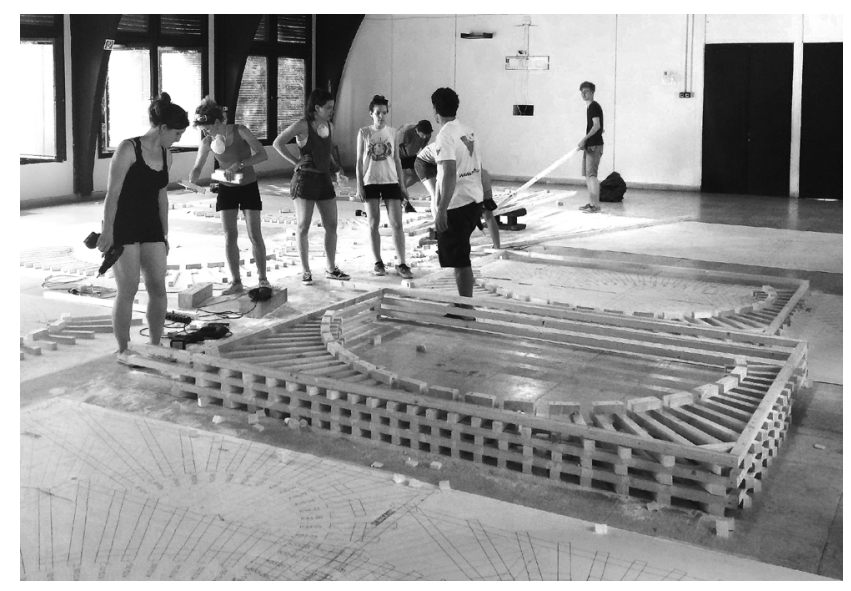

Fig. 8 Template drawing and some frames with rods

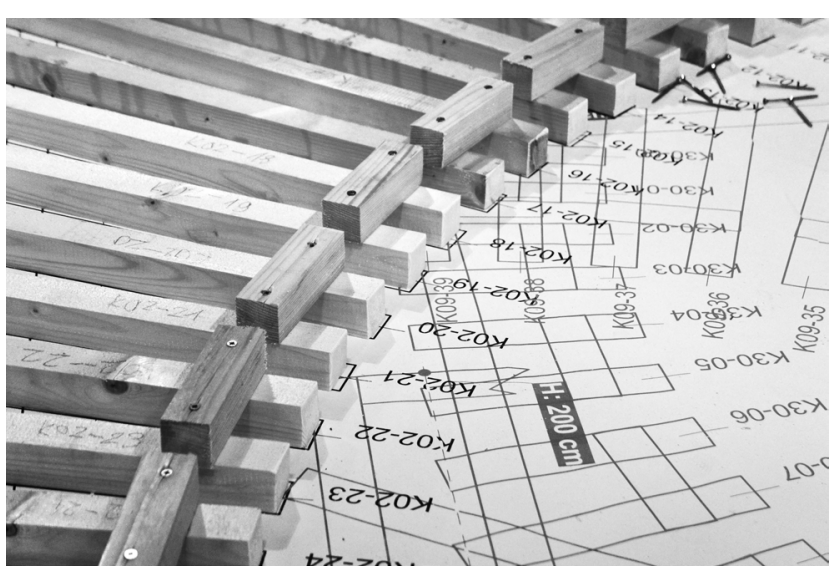

Fig. 9 Template drawing with rod schedules 


\section{Conclusion}

The Ammoniterasz is the cooperation of mathematical, geographical, and architectural and engineering design processes. An experimental artwork, to demonstrate how the traditional and digital design processes can complement each other.

The two main lessons of the completed wood structure are that a biological model can be the muse of the architect, not only a morphological copy; also, the formation process can be a model for the design. If we had not concentrated on the well-known form, we also could have gone for unknown solutions, as Bruce Mau declares:

"Process is more important than outcome. When the outcome drives the process, we will only ever go to where we've already been. If process drives outcome, we may not know where we're going, but we will know we want to be there." (Mau, 1998)

In another way, the existing digital, computational techniques are also real techniques in larger scale building designs. Complex spaces, structures could be illustrated by this technique, making it easier to analyse them and make it possible to construct them in practice; opening the door into the world of unknown architectural forms.

\section{References}

Deutsch, R. (2017) "Convergence: The Redesign of Design", John Wiley \& Sons Ltd., Chichester, UK.

Drew, P. (1976) "Frei Otto: Form and Structure", Westview Press, Boulder, Colorado, USA.

Hauschild, M., Karzel, R. (2011) "Digital Processes", Detail, Munich, Germany.

Gerber, D. J., Ibanez, M, (2014) "Paradigms in Computing", Evolo, New York, USA
The computer-driven, generative or computational design is a potential tool in the hands of the human architect, which together can increase productivity in many unimagined, and unique ways.

\section{Acknowledgement}

This research was made possible by Hello Wood. Thanks to Budapest University of Technology and Economics, Faculty of Architecture for institutional support and to our colleague Márton Nagy DLA. Special thanks to all the students at BME who took part in the workshop, namely Fruzsina Ács, Zsófia Berczi, Blanka Gáspárdy, Detti Kolossváry, Simon Kőszegi, Dóra Nagy, Csaba Pintér, Zsófia Sörényi, Zsófia Telek.

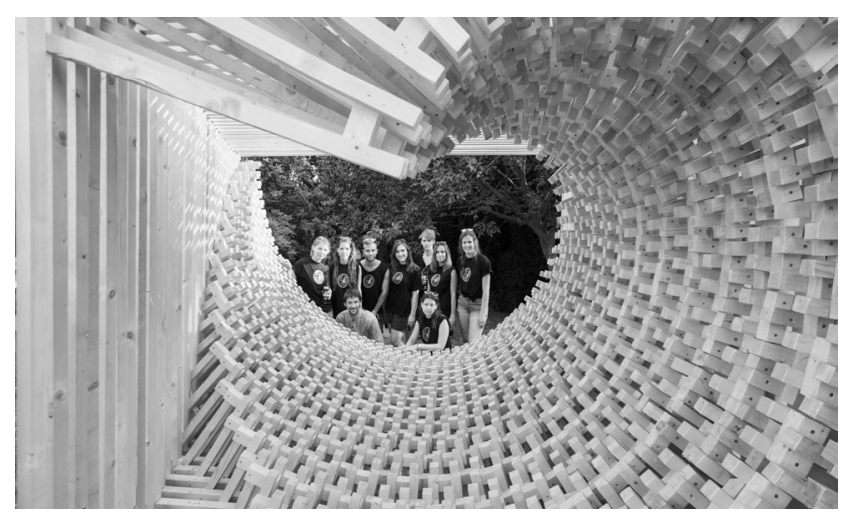

Interview with Reima Pietilä. See Suomen rakennustaiteen museo. (1985) "PIETILÄ - Modernin arkkitehtuurin välimaastoissa", (Intermediate Zones in Modern Architecture), Martinpaino, Helsinki, Finland, [Exhibition Publication]. (in Finnish)

Mau, B. (1998) Incomplete Manifesto for Growth. [online]. Available at: http://www.manifestoproject.it/bruce-mau/ [Accessed: 10 September 2016] 